cardiovascular disease, and patients who have had upper abdominal or thoracic surgery or prolonged nitrous oxide anaesthesia are among those who, you suggest, should be given routine oxygen postoperatively. Should this large group of patients have arterial $\mathrm{PO}_{2}$ and $\mathrm{PCO}_{2}$ measurements before, during, and after oxygen therapy? This would necessitate repeated stabs or an indwelling arterial line. Although Nunn ${ }^{1}$ felt there was no alternative to arterial puncture and direct measurement of $\mathrm{PO}_{2}$ we $^{2}$ have shown, using paired radial artery samples and arterialised capillary blood from the ear lobe, a highly significant correlation between both methods for $\mathrm{Po}_{2}$ determination. Respiratory care in the surgical unit would be improved by more frequent blood gas analysis, and arterialised capillary blood, when carefully collected, gives as accurate results as arteria blood.

For how long should oxygen be prescribed after general anaesthesia? Many surgical units routinely treat selected patients with oxygen for the first $24 \mathrm{~h}$ postoperatively. However, we $^{3}$ have shown that the mean percentage decrease in $\mathrm{PO}_{2}$ following upper abdominal surgery was greatest during the second and third postoperative days, remained greater than $20^{\circ}$, for the first four days, and tended to return to preoperative values towards the end of the first week. This suggests that when oxygen is indicated during the first postoperative day it is illogical to stop it after $24 \mathrm{~h}$ unless cessation is accompanied by seria observation of $\mathrm{PO}_{2}$ levels. Further treatment with oxygen should take into consideration the necessity for early mobilisation, oxygeninduced pulmonary toxicity, and the need to keep the arterial $\mathrm{Po}_{2}$ above $8 \mathrm{kPa}(60 \mathrm{~mm} \mathrm{Hg})$.

P S PARFREY

Medical Unit, London Hospital

London E1

Paul J Harte

J P QUINLAN

$M$ P BRADY

Department of Surgery,

University College,

Nunn, J F, Applied Respiratory Physiology. London, Butterworths, 1969

Parfrey, P S, et al, British fournal of Surgery, 1977, 64,

Parfrey, P S, et al, British fournal of Surgery, 1977, 64,
390.

\section{Naming of drugs}

SIR,-I heartily agree with Dr G A MacGregor's (18 November, p 1433) view that the multiplicity of names for one and the same drug is fraught with dangers. I do not, however, believe with you that the advice to use approved rather than proprietary names when prescribing drugs provides a satisfactory solution. This is a losing battle. After all, it is the proprietary name that appears in large letters on the bottle of tablets we get from the drug house, that appears in our medical journals and on the advertisements that come daily through our letterboxes, whereas the approved name is in tiny print and often difficult to find. Furthermore, in $M I M S$ drugs are listed according to their proprietary and not according to their approved names. Approved names, especially when attempts are made to indicate the pharmacological group to which they belong, become clumsy tonguetwisters like chlordiazepoxide or tranylcypro- mine, which makes them difficult to remember and to use when communicating with the nursing staff, not to mention the patients. A further hazard in these days of world travel lies in the fact that even some of our approved names are quite unknown abroad, including the USA, so that a patient travelling to foreign country might be in real trouble if he has left his tablets behind and tries to get them replaced abroad.

To my mind the best, if utopian, solution would be an international agreement: one single name for each drug. It should be simple, easily remembered, and universally understood. Should the prescriber be anxious to have a particular brand he should put the manufacturer's name in brackets behind the drug's name. It has worked so well for so long with insulin; why not for other drugs too?

\section{University Department of Therapeutics}

\section{R SCHNEIDER}

and Clinical Pharmacology,

Queen Elizabeth Hospital,

Birmingham

\section{Successful defibrillation in general practice}

SIR,-Drs A D Shaw and J L Baird (30 September, $p$ 958) suggested that their experience of resuscitation after cardiac arrest in general practice was unique. We are glad to say that it is not unique as we are able to report a further case.

The patient, a woman, suffered cardiac arrest in our surgery. External cardiac massage was started, an intratracheal tube was passed, and an intravenous line inserted. One of the partners went to the GP hospital and collected the electrocardiograph, which took well over five minutes; once attached it showed ventricular fibrillation. She was given $1 \mathrm{~g}$ of procainamide with no effect. At about this point the ambulance arrived, but unfortunately it did not have a defibrillator on board and was therefore sent to the district hospital to collect the recently donated portable machine, which naturally took a considerable amount of time, say 10 minutes. Luckily the casualty sister arrived with the defibrillator and a box of emergency drugs so that we were able to give the patient some bicarbonate. After problems with ventricular tachycardia asystole, a total of four defibrillations, and a mixture of drugs she was dispatched to the coronary care unit in sinus rhythm. She has now returned home to live alone with minimal amount of residual cardiac failure.

D J DICKSON

J M CRUICKSHANK

D W L SMITH

Northallerton, $\mathrm{N}$ Yorks

lack of communication and, more important, the service either group is able to give the patient is therefore impaired. I strongly fee that medicine has now become such a vast subject that there is a greater need than ever for each group, expert in its own particular branch of the science, to work with the other groups to provide an effective health service. Although the prophets of doom foretell the imminent destruction of the NHS, I look forward to an improved service in which I will be able to utilise my pharmaceutical education to its full potential to the benefit of the rest of the medical profession and the patients.

Bridgwater, Sornerset

Steven A Pleece

\section{Terminology of enuresis}

SIR,-The introduction of the term "recentonset enuresis" by Mr Paul H Abrams and others (4 November, $p$ 1258) to describe nocturnal incontinence due to chronic retention requires comment. At the recent meeting of the International Continence Society in Manchester an attempt was made to clarify the meaning of the term "enuresis" with little success. Enuresis simply means incontinence of urine, but by common usage has come to mean bed-wetting in children. It is a symptom and not a disease entity. During the time a child is "learning" bladder control incontinence is normal, only becoming abnorma when delay in gaining control is prolonged beyond 5 years of age. Keith Turner $^{1}$ has defined nocturnal enuresis as persistent involuntary micturition during sleep in the absence of demonstrable pathology. It is probably true that children who gain control both by day and by night and then become incontinent in the absence of demonstrable organic disease have a psychological basis for the incontinence. ${ }^{2}$ This group has been termed secondary or "onset" enuresis. Neither of these terms gives a clear description of the suggested aetiology. To clarify the situation it would seem that the term enuresis should be used in children or adults who fail to gain bladder control and as evidence of this have persistently wet the bed all their lives and have no demonstrable organic disease. I feel the introduction of the term "recent-onset enuresis" to describe nocturnal incontinence of known cause is a retrograde step and will add further to the confusion.

JOHN R HINDMARSH

Department of Surgery (Urology),

Western General Hospital Edinburgh

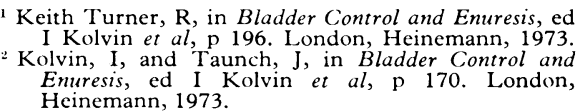

\section{Collaboration between GPs and}

pharmacists

SIR,-As a pharmacist working in retail pharmacy I am very concerned by the lack of co-ordination between general practitioners and retail pharmacists. Although I have no problems with my particular local practice, I find that if I have to refer back to other prescribers for various reasons I am not accepted as being able to discuss drug therapy on a level with them.

I do not wish to use your journal merely to voice my moans, but $I$ do feel that both GPs and pharmacists are the poorer for this

\section{Deficiencies in parenteral nutrition}

SIR,-Your leading article (30 September, p 913) wisely stresses that the advantages and disadvantages of parenteral feeding need to be carefully balanced, and jaundice and cholestasis are mentioned among the hazards associated with this form of therapy. The author of the reference cited concluded that cholestasis and jaundice occurring in :he patients whom he studied were produced by the intravenous amino-acid solution Travasol 1 In Great 
Britain this solution is called Synthamin. Recently minor elevations of serum bilirubin concentration and major elevations of serum alkaline phosphatase and aspartate aminotransferase activities have been observed in six patients receiving this solution following surgery of the head and neck. These patients did not have evidence of metastatic disease and no abnormalities have been observed in patients undergoing similar operations who did not receive nutritional support.

However, the same type of biochemical abnormalities have been seen in a patient receiving the intravenous amino-acid solution Vamin. Furthermore, 15 patients who received a nasogastric diet based on the beef protein derivatives Albumaid or Serameen and the glucose polymer Caloreen showed the same biochemical response. This latter observation would suggest that cholestasis occurring in patients receiving intravenous nutrients is unlikely to be due to a lack of stimulation of bile flow by food in the gut. Are these changes due to the absence of some dietary component or presence of some chemical agent that is common to artificial diets whether given intravenously or by the nasogastric route? These results will be reported in detail elsewhere. ${ }^{2} 3$

David TWeEdLe

F D SKIDMORE Neville Gleave

Department of Surgery University Hospital of South Manchester, Manchester

Allardyce, D B, in Advances in Parenteral Nutrition, Allardyce, D B, in Advances in Parenteral $N$

2 Skidmore, F D, et al, Annals of the Royal College of Surgeons of England. In press.

${ }_{3}$ Tweedle, D E F, et al, Research and Clinical Forums. In press.

\section{Primary autoimmune diabetes mellitus}

SIR,-We were interested in the further evidence provided by Dr G F Bottazzo and his colleagues (4 November, $p$ 1253) in support of a primary autoimmune type of diabetes mellitus (type 1a). Our own experience, including 61 ( 6 male, 55 female) insulin-dependent diabetics (IDDs) with coincident Graves's disease and 107 (16 male, 91 female) IDDs with primary thyroid failure confirms the characteristics of such a group of IDDs to include female preponderance, lack of seasonal variation in incidence, late age of onset, and a strong family history of organ specific autoimmune diseases including insulin-dependent diabetes.

Dr Bottazzo and his colleagues estimate that type 1a diabetics account for less than $10 \%$ of insulin-dependent patients but provide no evidence in support of this figure. We have considered the prevalence of the more common organ-specific autoimmune diseases in $445 \mathrm{IDDs}$ attending the diabetic outpatient department of this hospital consecutively during the months April and May 1978. We found $23(5 \cdot 2 \%)$ to have had Graves's disease, $11(2.4 \%)$ to have overt primary hypothyroidism, $14(3.2 \%)$ to have pernicious anaemia, and one to have Addison's disease. Allowing for one patient who had both pernicious anaemia and Graves's disease, 48 patients $(10.8 \%)$ had one or more organspecific autoimmune disease, of whom 37 $(77 \%)$ were female and $31(65 \%)$ were first recognised to be diabetic over the age of 30 years.

These figures do not take account of the prevalence of unrecognised thyroid failure in the diabetic population. Of 184 IDDs in whom a diagnosis of thyroid failure had not previously been suspected, $24(13 \%)$ had a raised serum thyrotrophin concentration, of whom $8(4.3 \%)$ had a low serum thyroxine concentration.

Thus we are confident that Dr Bottazzo and his colleagues have underestimated the proportion of IDDs who should be included in the category of type la diabetics.

R S GRAY B F CLARKE

Diabetic and Dietetic Department, Royal Infirmary,

Royal Infirm

\section{Tetracycline preparations for children}

SIR,-Dr R J Rowlatt's remarks (18 November, $\mathrm{p}$ 1436) on this subject prompt me to report the following information on the extent of prescription of these preparations.

I examined all prescriptions issued during February 1976 by a randomly selected sample of 12 general practitioners in the Grampian Area. A total of 328 prescriptions for tetracyclines had been issued, but only seven of these were for liquid tetracycline preparations. Four of the 12 doctors were responsible for these prescriptions and each had issued from one to three prescriptions for liquid tetracycline during the month in question, the mean quantity per prescription being $150 \mathrm{ml}$.

Not all of these prescriptions for liquid tetracycline would necessarily have been issued to children. The information therefore suggests that, in this area at least, the prescription of tetracyclines to children had been reduced to insignificant levels by 1976 .

Department of General Practice,

Ross J TAYLOR

Department of General
University of Aberdeen

\section{Practical problems with insulin \\ infusion pumps}

SIR,-In their article on the use of intravenous insulin infusions in diabetic emergencies (11 November, p 1343) Drs R D G Leslie and J D Mackay mention that on two occasions the insulin infusion pump was accidentally switched off. We have encountered simila practical problems with the use of infusion pumps in the management of diabetic ketoacidosis. On two occasions the connection at the proximal end of the drip tubing has been slightly dislodged from the indwelling intravenous cannula by restless, uncooperative patients and the pump has subsequently infused the bedclothes rather than the patient. On two further occasions a three-way tap situated between the pump and the patient has been inadvertently closed, resulting in failure of insulin delivery. We have even seen failure to switch on the mains supply. Fortunately these slips have had no serious consequences, but they nevertheless illustrate the potential for human error in the use of these pumps, which we feel detracts seriously from their value in acute situations. Mishaps are more likely to occur and to remain undetected in restless, semicomatose patients, who may tug endlessly at the drip tubing.

The practical difficulties of supervising the insulin infusion in addition to the various othe lines, catheters, and monitor leads while also perhaps restraining the patient are obvious, and it is hardly surprising that mishaps occur, even with the best nursing care and adequate staffing. Since the benefits of low-dose intravenous over low-dose intramuscular insulin therapy are marginal it would seem sensible to use the latter, safer, route in diabetic ketoacidosis. These remarks do not apply to the use of insulin infusion pumps in less critical situations, such as in the postoperative management of diabetic patients, where they are much safer and undoubtedly effective.

Hugh Mather

T R E PILKINGTON

Department of Medicine II, St George's Hospital Medical School, London SW 17

\section{Data sheets and lactation}

SIR,-As authors of the $\operatorname{articles}^{12}$ on drugs and breast-feeding described by Dr C D E Morris (18 November, p 1435) as "incomplete, inaccurate, and misleading" may we comment on his letter? Dr Morris complains that UK drug data sheets contain no reference to safety of the drug for use in lactating women. However, quantitative information on drug transfer in milk is available for very few drugs. Similarly the maximum "safe" dose of almost any drug taken by a suckling neonate in breast milk is unknown. For the majority of drugs, then, their safety in this context is still a matter of judgment, the exception being those drugs which we listed as contraindicated, such as carbimazole and amantadine, where definite adverse effects have been reported. More research on drug transfer is desirable.

In this situation it is not possible for precise advice to be included in the majority of drug data sheets. In our articles we attempted to help doctors by pointing out that centrally acting drugs (anticonvulsants, sedatives, etc) have low plasma levels in relation to effective oral doses so that the concentration of drug in breast milk will generally be low also. The majority of these drugs will therefore be safe for lactating women to take, but no drug manufacturer could state this categorically in a document for which he has legal responsibility. If a statement in the data sheet is made compulsory, then most companies will play safe and recommend that the drug be withdrawn during breast-feeding.

P J LEWIS

D R HARVEY

Institute of Obstetrics and

Gynaecology,
Queen Charlotte's Maternity Hospital, Lewis, P, fournal of Maternal and Child Health, 1978,
3, 128. .
Harvey, D, Modern Medicine (Great Britain), 1978,
23, 87.

\section{Breakfast and Crohn's disease}

SIR,-I venture to claim that the data of Dr J F Mayberry and others (18 November, p 1401) support my own ${ }^{1}$ provided that equivalent figures are compared. In my study I took account of pre-illness habit. Their tabulated data record current habit, but they go on to tell us that 33 of the patients and 13 of the controls had stopped eating cornflakes, having previously taken them regularly. It follows that if pre-illness habit had been 